\title{
Key feasibility considerations when conducting vaccine clinical trials in Asia-Pacific countries
}

This article was published in the following Dove Press journal:

Vaccine: Development and Therapy

18 March 2013

Number of times this article has been viewed

\author{
Elvira Zenaida Lansang' \\ Kenneth Tan ${ }^{2}$ \\ Saumya Nayak' \\ Ken J Lee' \\ Karen Wai'
}

'Feasibility and Site Identification Asia, Quintiles East Asia Pte Ltd, Singapore; ${ }^{2}$ National University of Singapore, Singapore

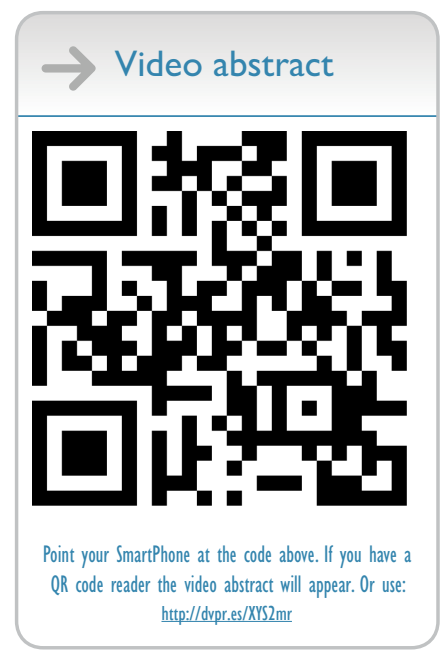

Correspondence: Elvira Zenaida Lansang Feasibility and Site Identification - Asia, Quintiles East Asia Pte Ltd, 79 Science Park Drive, \#06-08, Cintech IV, Science Park One, Singapore II 8264

Tel +6566021634

Fax +6568720430

Email elvirazenaida.lansang@quintiles.com
Introduction: Conducting clinical trial feasibility is an important first step in initiating a clinical trial. A robust feasibility process ensures that a realistic capability assessment is made before conducting a trial. A retrospective analysis of vaccine clinical trials was performed to understand changes which could affect feasibility recommendations.

Methods: Feasibilities conducted by Quintiles between January 2011 and August 2012 were reviewed. Vaccine studies only involving Asia-Pacific countries were selected, and common study parameters were identified. Information from Quintiles' database was retrieved to examine changes in parameters over time.

Results: A total of six vaccine studies were identified within the 1.7-year period. Two studies were excluded because they did not contain feasibility information or had involved sites that were sponsor selected. Four studies were analyzed. Three cases required healthy volunteers, while one case involved a specific patient population. Age requirement and seasonality of disease mainly influenced recommendations for Study 1. Sponsor's marketing strategy influenced the recommendations for Study 2. Study 3 showed the effect of a country's immunization program and reimbursement of vaccines on a study's success. In contrast to the other studies, Study 4 demonstrated the impact of eligibility criteria in recruitment recommendations for a vaccine trial requiring specific patient pools.

Conclusion: Feasibility recommendations for vaccine trials are largely based on (1) eligibility criteria; (2) cultural beliefs; (3) country's past recruitment performance; (4) use of advertising; (5) site's access to subject populations; (6) cooperation with local health professionals and government; (7) sponsor's marketing strategies; (8) study design concordance with national immunization programs; (9) reimbursement of vaccines; (10) overall benefit of the vaccine to the population; and where applicable, (11) seasonality of the disease under study.

Keywords: volunteers, recruitment, influenza, meningococcal, diphtheria, herpes zoster

There has been substantial progress in global health over the past several decades due to the benefits derived from successful implementation of immunization programs. ${ }^{1}$ To build on the remarkable success of vaccines and the global eradication of smallpox, the World Health Organization (WHO) established the Expanded Program on Immunization (EPI) to ensure that children in all countries have access to vaccinations. ${ }^{2}$ Although immunization benefits brought about by the EPI have prevented an estimated 2.5 million child deaths every year, there is still a need to introduce new vaccines in order to reduce the high toll of sickness, disability, and deaths among children and adults. ${ }^{3}$ Before a new vaccine is approved for market release, stringent regulatory procedures and clinical trials are performed to assess the quality, safety, and efficacy of the vaccine. ${ }^{4}$ All developed countries have a reliable submit your manuscript $\mid$ www.dovepress.com

Dovepress

http://dx.doi.org/10.2147/VDT.S41903
Vaccine: Development and Therapy 2013:3 I-9

(C) 2013 Lansang et al, publisher and licensee Dove Medical Press Ltd. This is an Open Access article which permits unrestricted noncommercial use, provided the original work is properly cited. 
National Regulatory Authority to oversee vaccine trials, but developing countries may lack the capacity to meet global standards and requirements. Therefore, the WHO has spearheaded a prequalification system to advise United Nations vaccine procurement agencies on the purchase of vaccines. ${ }^{3}$ A revised prequalification procedure by the WHO in 2012 requires that vaccine efficacy data and studies be relevant to the target population and meet specific needs of the program. ${ }^{5}$ In addition, the US Food and Drug Administration has set out guidance standards for clinical trial data in order to facilitate a Biologics License Application for marketing approval of vaccines. ${ }^{6}$ These programs and guidelines set out by world governing bodies will greatly influence vaccine clinical trials and may play a role in country selection, study sample size, and recruitment.

A contract research organization (CRO) is a service company that provides various clinical trial services to pharmaceutical and biotechnology companies (hereby denoted as sponsors). In recent times, clinical trials have become more complex and require larger patient populations, contributing to rising research and development costs. As a result, there is an increasing trend for sponsors to outsource their clinical trial activities to CROs in order to increase research and development effectiveness and lower costs. ${ }^{7,8}$ When sponsors decide to outsource a clinical trial, it is common for them to solicit a request for a proposal from different CROs. These proposals contain information on the cost of outsourcing the clinical trial to the $\mathrm{CRO}$ as well as detailed strategies on how the CRO plans to manage the clinical trial. Preliminary information on the feasibility of the trial is often a component of the proposal.

Asia is becoming increasingly important for clinical trials since the emerging pharmaceutical and biotechnology markets in the People's Republic of China, Japan, and other Asian countries are very promising from a commercial point of view. The biological market in the People's Republic of China is estimated to be growing at least $30 \%$ annually, while Japan represents approximately $7.3 \%$ of the worldwide pharmaceutical market. ${ }^{9}$ Since Asia consists of both developed and developing countries, it has a large patient population with diseases of both the developed and developing world. This is in addition to the potential for cost savings and fewer competing trials as compared to North America and Europe. ${ }^{8,10}$ The epidemiological profile of the Asian population is also unique due to its relatively high natural exposure to infections and naive immunological background. ${ }^{9}$ This makes Asian countries an especially attractive place to study new vaccines with rapid recruitment of trial subjects.
In this paper we seek to demonstrate the feasibility parameters that should be considered for vaccine trials. The purpose of this study is to retrospectively analyze the feasibility process of vaccine trials in order to: (1) identify the parameters that experience changes during feasibility and (2) evaluate the reasons behind the changes and how they affected final recommendations.

\section{Methods}

Quintiles is a contract research organization that provides clinical trial services for sponsors worldwide. This retrospective analysis was conducted by Quintiles Regional Feasibility and Site Identification Asia between January 2011, and August 2012. Feasibility requests were consistently tracked in Asia since January 2011, making retrieval of relevant records possible. All feasibility records that only involved Asia-Pacific countries received by Quintiles over the 1.7- year period were analyzed and collated. From the list of projects, vaccine studies that involved sponsor preference (eg, sponsor chose the sites or provided the patients) or did not involve any feasibility recommendations were excluded. An outline of the study scheme is represented in Figure 1.

Common trial parameters associated with feasibility recommendations were identified from the studies. These included (1) study timelines, (2) countries, (3) age group, (4) number of patients, (5) reimbursement status of the investigational product, (6) impact on the country's immunization program, and (7) the method of obtaining the information. These parameters were compared to the

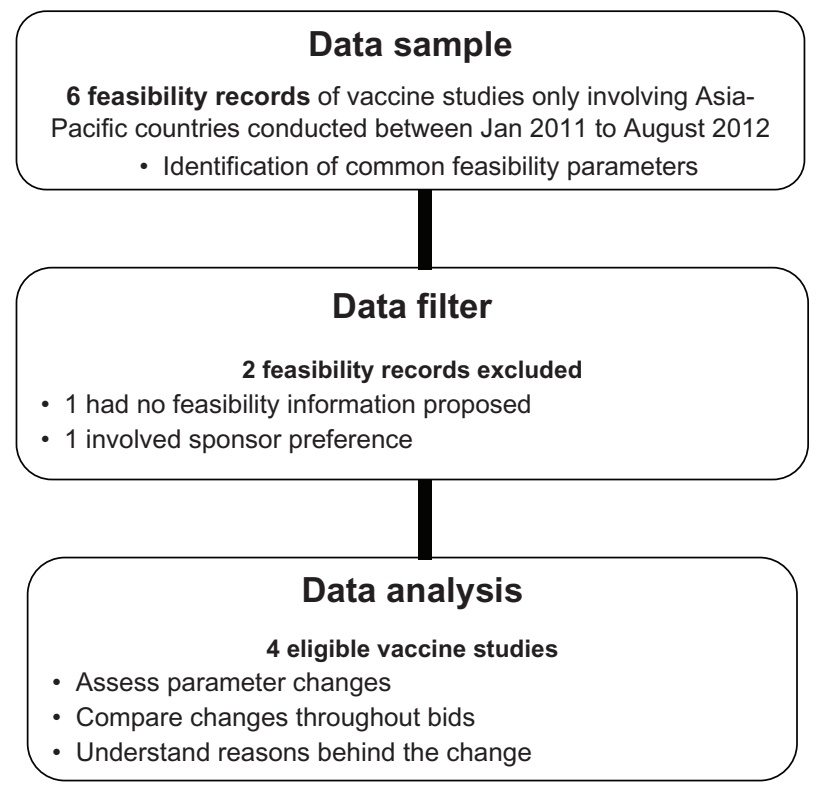

Figure I Outline of the study scheme. 
feasibility recommendations, such as the countries, number of sites, and recruitment rates proposed. The definition of the respective feasibility parameters is shown in Table 1. Country level capability refers to the recommendations provided by local feasibility experts on the potential number of sites and the expected number of patients that can be recruited in each site per month. Final recommendations refer to the list of countries, site number, and expected recruitment rate that Quintiles proposed to deliver the study.

To assess how the parameters affected subsequent recommendations, data from Quintiles' proprietary database and internal communications were analyzed to track changes throughout the different time points. The reason for changes, if applicable, was also determined in order to understand the rationale.

\section{Results}

A total of six vaccine studies were identified over the 1.7-year period. Of these six studies, two were excluded from analysis: one study was a proposal to conduct feasibility and did not include any feasibility recommendations; one study had sites and investigators that were already identified by the sponsor. Hence, four vaccine studies were selected for analyses.

Whenever Quintiles receives a request for a proposal from a sponsor to conduct a clinical trial, the feasibility of the protocol is evaluated using various parameters. The selection of the $\mathrm{CRO}$ to conduct the clinical trial often involves a bidding process and may span several months. During this process the sponsor may revise some protocol specifications (eg, patient numbers, study timelines, eligibility criteria, countries).
These changes are evaluated by Quintiles' experts in each country through mining of internal databases and/or investigator outreach. A recommendation that includes the number of sites and anticipated recruitment rate is then made on the feasibility of the trial in each country. These recommendations are analyzed at an Asia-regional level to come up with the final list of countries, number of sites, and expected recruitment rates for the entire study. Studies 3 and 4 do not contain any final recommendations because Quintiles provided the cost for the actual specifications from the sponsor. Quintiles is conducting three (out of the six) vaccine clinical trials that were identified. Tables 2-5 describe the changes in the feasibility parameters for the four vaccine studies that were analyzed. For confidentiality, the countries involved have been blinded to their regional location (eg, two Southeast Asian [SEA] countries would be described individually as SEA 1 and SEA 2).

Study 1 is an influenza vaccine study and involved three time points where Quintiles proposed different strategies based on changes in study parameters, which the sponsor set. The purpose of conducting Study 1 was to obtain WHO prequalification (WHO-PQ) of the vaccine. During the time points, the target countries and age distribution of the trial subjects that the sponsor required were revised, influencing the proposed site numbers and recruitment rates.

Study 2 is a meningococcal vaccine study to be conducted in a SEA country. The sponsor revised the study parameters/ expectations in two instances, prompting Quintiles to revise its strategy. In contrast to Study 1 , the target country, target number, and age group of trial subjects required remained constant through both time points.

Table I Definition of feasibility parameters

\begin{tabular}{|c|c|}
\hline Parameters & Definition \\
\hline Study timelines & $\begin{array}{l}\text { The expected date on the availability of the final protocol and the date when the last patient is } \\
\text { expected to be enrolled into the trial. }\end{array}$ \\
\hline Countries requested & Countries that were considered for the feasibility assessment. \\
\hline Eligibility criteria & Main inclusion criteria of healthy volunteers/patients that may be included in the trial. \\
\hline Number of patients & The target number of patients required for the trial. \\
\hline Reimbursement status of investigational product & $\begin{array}{l}\text { Whether or not the national health insurance of the government reimburses the vaccine in the } \\
\text { subject population. }\end{array}$ \\
\hline Impact on the immunization program & $\begin{array}{l}\text { Whether or not the administration of the study vaccine interferes with the country's } \\
\text { immunization program. }\end{array}$ \\
\hline Country level capability - number of sites & $\begin{array}{l}\text { Recommendation of country feasibility expert on the potential number of sites that are available } \\
\text { and capable to conduct the trial. }\end{array}$ \\
\hline Country level capability - recruitment rate & $\begin{array}{l}\text { Recommendation of country feasibility expert on the potential number of patients that can be } \\
\text { recruited by each site in I month. }\end{array}$ \\
\hline $\begin{array}{l}\text { Final countries, site number, and expected } \\
\text { recruitment rate to deliver the study }\end{array}$ & $\begin{array}{l}\text { Quintiles' recommendations on the expected countries, number of sites, and recruitment rate for } \\
\text { the trial. }\end{array}$ \\
\hline Method of obtaining information & $\begin{array}{l}\text { The method that was utilized to gather information needed for proposing feasibility } \\
\text { recommendations. (Internal data mining refers to internal data review. Investigator outreach } \\
\text { involves communicating with potential investigators and obtaining possible recruitment estimates.) }\end{array}$ \\
\hline
\end{tabular}


Table 2 Study I (influenza vaccine, healthy volunteers): parameters and how they affected feasibility recommendations

\begin{tabular}{|c|c|c|c|}
\hline Parameters & Sep 2011 & Dec 20 I I & Mar 2012 \\
\hline \multirow[t]{2}{*}{ Study timelines } & Final protocol: Feb I, 2012 & Final protocol: Feb I, 2012 & Final protocol: May 15, 2012 \\
\hline & LPI: Nov 30, 2012 & LPI: Nov 30, 2012 & LPI: Mar 15, 2013 \\
\hline \multirow[t]{3}{*}{ Countries requested } & SEA I & SEA I & EA I \\
\hline & SEA 2 & SEA 2 & EA 2 \\
\hline & & SEA 3 & SEA 4 \\
\hline Expected influenza & SEA I: May-Aug & SEA I: May-Aug & EA I: Dec-Feb and Apr-Jul \\
\hline \multirow[t]{2}{*}{ season $^{31-36}$} & SEA 2: Jun-Oct & SEA 2: Jun-Oct & EA 2: Dec-Feb and Jun-Nov \\
\hline & & SEA 3: Dec-Feb & SEA 4: Dec-Apr \\
\hline \multirow[t]{5}{*}{ Age groups } & Three stratified groups of healthy & Three stratified groups of healthy & Healthy adults only \\
\hline & volunteers: pediatrics/adolescent & volunteers: pediatrics/adolescent & \\
\hline & (6 months- 17 years) & (6 months- 17 years) & \\
\hline & Adult & Adult & \\
\hline & Elderly ( $>75$ years) & Elderly (>75 years) & \\
\hline Number of subjects & Total $(900)$ & Total $(I \mid 50)$ & Total $(400)$ \\
\hline \multirow[t]{3}{*}{ requested } & Ped (300) & Ped $(150)$ & \\
\hline & Adults (300) & Adults (850) & \\
\hline & Elderly (300) & Elderly (I50) & \\
\hline \multicolumn{3}{|l|}{ investigational product } & No \\
\hline Impact on the country's EPI & No impact & No impact & No impact \\
\hline Country level capability - & SEA I (3 sites) & SEA I (5 sites) & EA I (2 sites) \\
\hline \multirow[t]{2}{*}{ number of sites } & SEA 2 (4 sites) & SEA 2 (4 sites) & EA 2 (4 sites) \\
\hline & & SEA 3 (3 sites) & SEA 4 (3 sites) \\
\hline Country level capability - & SEA I (35 ppspm) & SEA I (2I ppspm) & EA I (4 ppspm) \\
\hline \multirow[t]{2}{*}{ recruitment rate (Ppspm) } & SEA 2 (90 ppspm) & SEA 2 (72 ppspm) & EA 2 (I5 ppspm) \\
\hline & & SEA 3 (8 ppspm) & SEA 4 (67 ppsm) \\
\hline Final countries, site number, & SEA I (3 sites I 8 ppspm) & SEA I (5 sites 2 I ppspm) & SEA 4 (3 sites 67 ppspm) \\
\hline and expected recruitment & SEA 2 (4 sites 64 ppspm) & SEA 2 (4 sites 72 ppspm) & \\
\hline \multicolumn{4}{|l|}{ rate to deliver the study } \\
\hline Method of obtaining & Internal data mining & Internal data mining & Internal data mining and \\
\hline information & & & investigator outreach \\
\hline
\end{tabular}

Abbreviations: LPI, last patient in; SEA, Southeast Asia; EA, East Asia; EPI, expanded program of immunization; ppspm, patient per site per month.

Table 3 Study 2 (meningococcal vaccine, healthy volunteers): parameters and how they affected feasibility recommendations

\begin{tabular}{|c|c|c|}
\hline Parameters & Jan 201 I & Mar $201 \mathrm{I}$ \\
\hline \multirow[t]{3}{*}{ Study timelines } & Final protocol: & Final protocol: \\
\hline & May I5, 20II & May I5, 20II \\
\hline & LPI: Nov 29, 201 I & LPI: Nov 29, 201 I \\
\hline Countries requested & SEA I & SEA I \\
\hline \multirow[t]{2}{*}{ Age groups } & Healthy adults & Healthy adults \\
\hline & (18-55 years) & (18-55 years) \\
\hline $\begin{array}{l}\text { Number of subjects } \\
\text { requested }\end{array}$ & Total $(200)$ & Total $(200)$ \\
\hline $\begin{array}{l}\text { Reimbursement of } \\
\text { investigational product }\end{array}$ & No & No \\
\hline Impact on the country's EPI & No impact & No impact \\
\hline $\begin{array}{l}\text { Country level capability - } \\
\text { number of sites }\end{array}$ & SEA I (3 sites) & SEA I ( 2 sites $)$ \\
\hline $\begin{array}{l}\text { Country level capability - } \\
\text { recruitment rate (ppspm) }\end{array}$ & SEA I (I0 ppspm) & SEA I (66 ppspm) \\
\hline Method of obtaining & Internal data & Internal data mining \\
\hline information & mining & and investigator \\
\hline & & outreach \\
\hline
\end{tabular}

Abbreviations: LPI, last patient in; SEA, Southeast Asia; EPI, expanded program of immunization; ppspm, patient per site per month.
Study 3 is a diphtheria tetanus pertussis (DTP) pentavalent vaccine to be conducted in two SEA countries. Preliminary feasibility findings in the first time point showed that due to administrative reasons, there was a high likelihood of delayed regulatory approval in SEA 2. Study timelines were very critical; hence, an additional country was evaluated in the second time point to minimize the risk.

Unlike the first three cases that required healthy volunteers, Study 4 is a herpes zoster vaccine requiring immunocompromised patients. From March to August 2012, the sponsor decided to outsource this clinical trial over a number of countries (SEA 1, Pacifica 1, Pacifica 2, and East Asia [EA] 2). The sponsor had specific numbers of sites, patients, and recruitment durations for each country.

\section{Discussion}

Conducting clinical trial feasibility is an important step in initiating clinical trials. Global studies in recent times have shown that $35 \%$ of delays in studies were due to 
Table 4 Study 3 (DTP vaccine, healthy infants): parameters and how they affected feasibility recommendations

\begin{tabular}{|c|c|c|}
\hline Parameters & Jun 2012 & Jul 2012 \\
\hline Study timelines & $\begin{array}{l}\text { Final protocol: } \\
\text { August } 2012 \\
\text { LPI: April } 2013 \\
\text { Recruitment } \\
\text { duration: } 4 \text { months }\end{array}$ & $\begin{array}{l}\text { Final protocol: } \\
\text { August } 2012 \\
\text { LPI: April } 2013 \\
\text { Recruitment } \\
\text { duration: } 4 \text { months }\end{array}$ \\
\hline Countries requested & SEA 2 & $\begin{array}{l}\text { SEA I } \\
\text { SEA } 2\end{array}$ \\
\hline Age groups & $\begin{array}{l}\text { Healthy infants: } \\
8-12 \text { weeks of } \\
\text { age ( } 60-89 \text { days) }\end{array}$ & $\begin{array}{l}\text { Healthy infants: } \\
8-12 \text { weeks of } \\
\text { age ( } 60-89 \text { days) }\end{array}$ \\
\hline $\begin{array}{l}\text { Number of subjects } \\
\text { requested }\end{array}$ & Total $(550)$ & Total $(550)$ \\
\hline $\begin{array}{l}\text { Reimbursement of } \\
\text { investigational product }\end{array}$ & No & Yes \\
\hline $\begin{array}{l}\text { Impact on the } \\
\text { country's EPI }\end{array}$ & SEA 2: some impact & $\begin{array}{l}\text { SEA I: no impact } \\
\text { SEA 2: some impact }\end{array}$ \\
\hline $\begin{array}{l}\text { Country level capability - } \\
\text { number of sites }\end{array}$ & SEA 2 (2 sites) & $\begin{array}{l}\text { SEA I (4 sites) } \\
\text { SEA } 2 \text { (2 sites) }\end{array}$ \\
\hline $\begin{array}{l}\text { Country level capability - } \\
\text { recruitment rate (ppspm) }\end{array}$ & SEA 2 (275 ppspm) & $\begin{array}{l}\text { SEA I ( } 10 \text { ppspm }) \\
\text { SEA } 2 \text { ( } 275 \text { ppspm })\end{array}$ \\
\hline $\begin{array}{l}\text { Method of obtaining } \\
\text { information }\end{array}$ & $\begin{array}{l}\text { Internal data mining } \\
\text { and investigator } \\
\text { outreach }\end{array}$ & $\begin{array}{l}\text { Internal data mining } \\
\text { and investigator } \\
\text { outreach }\end{array}$ \\
\hline
\end{tabular}

Abbreviations: DTP, diphtheria tetanus pertussis; LPI, last patient in; SEA, Southeast Asia; EPI, expanded program of immunization; Ppspm, patient per site per month.

patient recruitment and nonenrolling sites, resulting in a much longer trial cycle time from first patient visit to last patient visit. ${ }^{11}$ Assessing feasibility helps in identifying such challenges early and provides recommendations to assist in planning with the overall objective of supporting optimum project completion, especially in terms of timelines, patient recruitment target, and costs. The ability of sites to recruit, the acceptability of the study design, the availability of staff and facilities to conduct the clinical trial, and the anticipated start-up timeline are important considerations in determining the most suitable countries to include in a clinical trial. Undertaken at an early stage in the site selection process, a robust feasibility will help to ensure that a clinical trial will be able to recruit a study population of an adequate sample size within a given period; it helps guarantee a realistic assessment of the capability to conduct a clinical trial. ${ }^{11}$

CROs and sponsors often assess the potential and interest of trial sites to conduct clinical studies through feasibility questionnaires. ${ }^{12}$ Feasibility questionnaires are sent to potential principal investigators to gather data on availability and access to the needed trial population, site facilities, and his/her clinical trial experience for a specific
Table 5 Study 4 (herpes zoster vaccine, immunocompromised patients): parameters and how they affected feasibility recommendations

\begin{tabular}{|c|c|}
\hline Parameters & August to March 2012 \\
\hline \multirow[t]{3}{*}{ Study timelines } & Final protocol: March 23, 2012 \\
\hline & LPI: Feb 28, 2014 \\
\hline & Recruitment duration: 18 months \\
\hline \multirow[t]{3}{*}{ Countries requested } & SEA I \\
\hline & Pacifica I, Pacifica 2 \\
\hline & EA 2 \\
\hline Age groups & Adults (aged $\geq 18$ years) \\
\hline Inclusion criteria & Immunocompromised patients \\
\hline \multirow[t]{4}{*}{ Number of patients requested } & Total $(92)$ \\
\hline & SEA I (I2) \\
\hline & Pacifica I and $2(60)$ \\
\hline & EA $2(20)$ \\
\hline $\begin{array}{l}\text { Reimbursement of investigational } \\
\text { product }\end{array}$ & No \\
\hline Impact on the country's EPI & No impact \\
\hline Country level capability - & SEA I (2 sites) \\
\hline \multirow{3}{*}{ number of sites } & Pacifica I (4 sites) \\
\hline & Pacifica 2 (2 sites) \\
\hline & EA 2 (4 sites) \\
\hline Country level capability - & SEA I (0.35 ppspm) \\
\hline \multirow[t]{3}{*}{ recruitment rate (ppspm) } & Pacifica I (0.58 ppspm) \\
\hline & Pacifica 2 (0.58 ppspm) \\
\hline & EA 2 (0.35 ppspm) \\
\hline Method of obtaining information & Internal data mining \\
\hline
\end{tabular}

Abbreviations: LPI, last patient in; SEA, Southeast Asia; EA, East Asia; EPI, expanded program of immunization; ppspm, patient per site per month.

therapeutic area, the likely recruitment rates, as well as on-going studies at the site or any regulatory or ethical issues that may compound start-up timelines..$^{13,14}$ Due to limited timelines in most instances, feasibility questionnaires may not be utilized. Instead, a CRO may perform a thorough analysis of the clinical trial landscape through the use of internal and external databases. The information derived from these sources contributes to the feasibility recommendations, including country, site, and patient strategies, for a trial. Several important considerations are evaluated when providing feasibility recommendations for vaccine trials.

Similar to any clinical trial, eligibility criteria play an important role in determining the recruitment rate. Unlike clinical trials involving drugs, however, vaccine trials typically recruit healthy volunteers. The age requirement of healthy volunteers participating in a vaccine study will largely influence the recruitment rate. Study 1 illustrates that a change in the age distribution of the healthy volunteers impacted the recruitment capacity at the sites. Investigators had predicted higher recruitment rates for pediatric and school-age populations versus the adult and elderly populations. This may be due to several reasons. 
Firstly, the vulnerability of children in acquiring infections could be a motivating factor for parents to involve their children in vaccine clinical trials. Secondly, it is relatively easier to engage school-age populations in vaccine trials versus the adult and elderly population because they are congregated in schools. Potential interruptions with work among adults and the presence of co-morbidities/logistical issues of transportation in the elderly can also decrease the subject pool in the adult and elderly population. According to a study by Allsup and Gosney, the top three reasons for noninvolvement of the elderly population in an influenza clinical trial include reluctance to participate in a research project, concerns about side effects, and self-perceived views of not requiring influenza vaccination. ${ }^{15}$ Ridda et al also identified participation, informed consent, access issues, subject fear/concerns, and morbidity and mortality as common barriers to the participation of the elderly in clinical trials. ${ }^{16}$ Thus, the age of subjects is a critical parameter in affecting recruitment recommendations.

Vaccine trials requiring a sick patient pool generally have much lower recruitment rates than healthy volunteer trials. ${ }^{17}$ The estimated recruitment rate largely depends on how stringent the inclusion and exclusion criteria are. The expected recruitment rates for Study 4 were mainly influenced by the number of immunocompromised patients in each country. This is certainly much lower than the healthy patient population.

Cultural beliefs in a country also influence the anticipated recruitment for a clinical trial. In Study 1, the proposed recruitment rate of EA 1 was lower than other countries because of the common belief that influenza vaccination was not effective and the general lack of willingness of the people to receive this vaccination. Research shows that health beliefs and cultural values influenced the uptake of influenza vaccine among older people. Unvaccinated subjects tended to prefer indigenous health practices, and natural methods, and did not believe in vaccine effectiveness. ${ }^{18,19}$ In Hong Kong, for example, a study revealed that the willingness of community nurses to accept influenza A vaccination was low, primarily due to concerns about the vaccine's effectiveness and side effects. ${ }^{20}$ Unless corrected, these beliefs may negatively influence recruitment for influenza vaccine trials.

Another key consideration in determining a country and site's capacity to recruit is the actual recruitment rates in previous similar clinical trials in conjunction with an investigator's projected recruitment rates for a given protocol. The recruitment rate proposed in January 2011 of Study 2 was based solely on the past recruitment performance in the country. Due to the limited timeframe in developing the response to the sponsor, Quintiles was unable to obtain investigator feedback on potential recruitment rates. In March 2011, the recruitment period was shortened, necessitating an increase in the number of sites and/or expected recruitment rates. Because there was sufficient time available to contact investigators, potential recruitment rates from investigators were sought and obtained. The higher recruitment rate of 66 patients per site per month was proposed as it was decided that it could be achieved through strong ethical advertising efforts in the university and public areas. Indeed, advertising methods were found to be necessary contributors to the recruitment success of a clinical trial, ${ }^{21,22}$ particularly when using multiple overlapping recruiting strategies and avenues. Past recruitment performance and aggressive ethical advertisements can therefore contribute positively to a site's recruitment capacity.

For vaccine trials requiring healthy volunteers, the utilization of electronic health records and patient census is less useful for recruitment. Instead, sites must have access to healthy populations, such as communities, schools, or universities, to successfully recruit large patient numbers. In addition to effective marketing strategies, community outreach and involvement can help bolster recruitment rates. A review on community-based trial participation by Viswanathan et al found that studies that featured community involvement often had improved participation rates. This was partially attributable to the fact that members of the community could provide better advice on more effective and culturally sensitive approaches to engage their fellow members, ultimately providing better comprehension of trial information to the volunteers. ${ }^{23}$ Furthermore, a crosssectional study by Costas et al showed that the influence of other people was an important motivating factor for joining a clinical trial. Most of the participants of their vaccine study knew people related to the study (eg, other participants who had already enrolled) and reported this as a motivation for participating. ${ }^{24}$ Clinical trial sites with access to local health centers amid communities have demonstrated recruitment success, particularly for those requiring healthy volunteers. Close communication and cooperation of the community with local health professionals and the government is also critical. ${ }^{25}$ The high recruitment rates of countries proposed for Studies 1, 2, and 3 have been made possible through the use of such sites. Therefore, sites with greater access to the communities and collaboration with local health professionals and governments are key factors to a clinical trial's success. 
At the other end of the spectrum, medical records, patient census, and registries are more useful for vaccine trials requiring patients. Access to these types of databases makes the identification of potential patients that fulfill the main eligibility criteria easier. Study 4 included a subset of immunocompromised patients, specifically those planning to undergo stem cell transplantation. Hence, the sites that conduct stem cell transplants in each country were considered for the trial. The average number of stem cell transplants conducted per year in the hospital was used as a basis in estimating the recruitment rate.

A sponsor's marketing strategy also influences country selection and recommendations. ${ }^{26}$ In Study 2, the sponsor specified the country where they planned to conduct the study. The country of choice was limited by its capacity to subsequently market the vaccine. As a consequence, other Asian countries offering recruitment rates potentially five times higher, based on Quintiles' past experience, were not considered. In Study 1, however, the main purpose of the trial was to obtain WHO-PQ of the vaccine. Thus, the trial could be conducted in any country that is able to produce clinical trial results that are compliant with WHO-PQ standards. Hence, it is always important to understand each sponsor's underlying reason for conducting a trial in order to recommend the best possible strategy.

Where applicable, the seasonality of a disease may also influence country recommendations for a vaccine trial. Study 1 illustrates that the influenza season coinciding with the expected recruitment period was one of the factors considered during country selection. In March 2012, a delay in the anticipated initiation of the study resulted in a different set of countries to be evaluated and eventually recommended to conduct the study. The influenza season of SEA 4 would coincide with the recruitment period. This case study demonstrated that seasonality of the disease under investigation can impact the country recommendations for a vaccine trial.

When country selection is not mandated by a sponsor's marketing strategies or vaccine seasonality, other influencing factors are the concordance with the national immunization program and availability of reimbursement for the vaccines. The vaccination schedule of the investigational product must have minimal impact on a country's immunization program. Regulatory and ethics committee approval and investigator interest are largely dependent on each subject's ability to receive the current standard of care on immunizations. ${ }^{27} \mathrm{As}$ with any clinical trial, it is advantageous to have minimal interference of a protocol to a country's standard of care. The protocol for Study 3 requires an 8-12-16-week DTP vaccination schedule. The sponsor requested that the study be conducted in SEA 2, a country with proven vaccine recruitment capabilities. The DTP vaccination schedule in the immunization program of SEA 2 follows a 6-10-14-week interval. Consultation with two investigators showed mixed reactions in the acceptability of this vaccination schedule because of a slight variation to the DTP vaccination schedule of the national immunization program.

The reimbursement status of the vaccine under study in a country will have a significant impact on country selection because it influences the potential recruitment rate for the vaccine clinical trial. For instance, if the vaccine is already available in the country and is reimbursed for the desired study population, there is less incentive for subjects to join the clinical trial. ${ }^{28}$ In Study 3, pentavalent DTP vaccine is already being used in many health clinics in SEA 1, leading to a lower overall recruitment rate compared to SEA 2. In order to make the trial more attractive for subjects, the sponsor considered adding rotavirus and/or pneumococcal virus into the study design.

When determining potential countries to conduct a vaccine trial, the overall benefit of the vaccine to the general population is also one of the factors to consider. Vaccines targeting a specific disease are best conducted in countries where the disease prevalence is high. This makes the research more ethical because subjects that are recruited are those who are more susceptible to the disease. ${ }^{29}$ There is also a longer term view of implementing these vaccines in the national immunization program. Schimpff states that when thinking of vaccines, the world can be divided into three types of countries, industrialized countries, those with transitional economies, and developing countries. ${ }^{30}$ Countries evaluated for Study 4 on herpes zoster immunization are developed countries. In contrast, the countries evaluated for Study 3 on DTP vaccination belong to the developing world. Indeed, DTP and Haemophilus Type B infections are among the key needs of immunization in the developing world. ${ }^{30}$

In conclusion, feasibility for vaccine clinical trials is a special niche with different key feasibility parameters for consideration. Feasibility recommendations for vaccine studies are largely based on (1) the eligibility criteria; (2) cultural beliefs; (3) past recruitment performance in similar trials; (4) the use of advertising as a recruitment strategy; (5) the site's access to healthy volunteer databanks, schools, communities and patient populations; (6) cooperation with local health professionals and the government; (7) the sponsor's marketing strategies; (8) the concordance of the study design with the national immunization program; (9) the reimbursement of vaccines; (10) the overall benefit of the vaccine to the population; and where applicable, (11) the seasonality of the disease 
under study. When determining the most suitable countries and sites to recommend in a vaccine clinical trial, the application of these feasibility parameters will need to be evaluated against the specific requirements of each protocol.

\section{Disclosure}

$\mathrm{K}$ Tan is a former contract employee of Quintiles. He has helped gather data and literature for this research. Mr Tan has not received any additional payment from Quintiles for the conduct of this research. The other authors report no conflicts of interest in this work.

\section{References}

1. Nieberg P, McLaren N. Role(s) of Vaccines and Immunization Programs in Global Disease Control, 1st ed. Washington, DC: Center for Strategic and International Studies, 2011.

2. Keja K, Chan C, Hayden G, Henderson RH. Expanded programme on immunization. World Health Stat Q. 1988;41(2):59-63.

3. WHO, UNICEF, World Bank. State of the World's Vaccines and Immunization, 3rd ed. Geneva: World Health Organization, 2009.

4. Jodar L, Duclos P, Milstien JB, Griffiths E, Aguado MT, Clements CJ. Ensuring vaccine safety in immunization programmes - A WHO perspective. Vaccine. 2001;19(13-14):1594-1605.

5. WHO. Procedure for assessing the acceptability, in principle, of vaccines for purchase by United Nations agencies. May 1, 2012. Available from: http://www.who.int/immunization_standards/vaccine_quality/ pq_revised_procedure_final_1 may2012.pdf. Accessed November 22, 2012.

6. US Food and Drug Administration. Guidance for industry: Clinical data needed to support the licensure of seasonal inactivated influenza vaccines. May 2007. Available from: http://www.fda.gov/ BiologicsBloodVaccines/GuidanceComplianceRegulatoryInformation/ Guidances/Vaccines/ucm074794.htm. Accessed November 22, 2012.

7. Mirowski P, Van Horn R. The contract research organization and the commercialization of scientific research. Soc Stud Sci. 2005;35(4): $503-548$.

8. Shuchman M. Commercializing clinical trials - risks and benefits of the CRO boom. N Engl J Med. 2007;357(14):1365-1368.

9. Kudrin A. Challenges in the clinical development requirements for the marketing authorization of new medicines in southeast Asia. J Clin Pharmacol. 2009;49(3):268-280.

10. Varawalla N. Conducting clinical trials in Asia. June 1, 2006. Available from: http://www.appliedclinicaltrialsonline.com/appliedclinicaltrials/ article/articleDetail.jsp?id=334577. Accessed December 14, 2012.

11. Rajadhyaksha V. Conducting feasibilities in clinical trials: An investment to ensure a good study. Perspect Clin Res. 2010;1(3):105-109.

12. Carson PA. Clinical research in dermatology - 10 steps to getting started. Dermatol Ther. 2006;19(6):377-382.

13. Sullivan J. Subject recruitment and retention: Barriers to success. April 1, 2004. Available from: http://www.appliedclinicaltrialsonline. com/appliedclinicaltrials/article/articleDetail.jsp?id=89608. Accessed November 20, 2012.

14. Burgess LJ, Sulzer NU. Examining the clinical trial feasibility process and its implications for a trial site. Open Access J Clin Trials. 2011;3: $51-54$.

15. Allsup SJ, Gosney MA. Difficulties of recruitment for a randomized controlled trial involving influenza vaccination in healthy older people. Gerontology. 2002;48(3):170-173.

16. Ridda I, MacIntyre CR, Lindley RI, Tan TC. Difficulties in recruiting older people in clinical trials: An examination of barriers and solutions. Vaccine. 2010;28(4):901-906.
17. Lovato LC, Hill K, Hertert S, Hunninghake DB, Probstfield JL. Recruitment for controlled clinical trials: literature summary and annotated bibliography. Controlled Clin Trials. 1997;18(4):328-352.

18. Kwong EW, Pang SM, Choi P, Wong TK. Influenza vaccine preference uptake among older people in nine countries. J Advanced Nursing. 2010;66:2297-2308.

19. Kwong EW, Lam IO. Chinese older people in Hong Kong: health beliefs about influenza vaccination. Nursing Older People. 2008;20(7): 29-33.

20. Wong S, Wong E, Chor J, et al. Willingness to accept H1N1 pandemic influenza vaccine: a cross-sectional study of Hong Kong community nurses. BMC Infectious Diseases [10.1186/1471-224-10-316]. 2010;10:316. Available from: http://www.biomedcentral.com/14712334/10/316. Accessed January 16, 2013.

21. Chin Feman SP, Nguyen LT, Quilty MT, et al. Effectiveness of recruitment in clinical trials: An analysis of methods used in a trial for irritable bowel syndrome patients. Contemp Clin Trials. 2008;29(2): 241-251.

22. Bjornson-Benson WM, Stibolt TB, Manske BA, Zavela KJ, Youtsey DJ, Buist AS. Monitoring recruitment effectiveness and cost in a clinical trial. Control Clin Trials. 1993;14:52S-67S.

23. Viswanathan M, Ammerman A, Eng E, et al. Community-Based Participatory Research: Assessing the Evidence. Evidence Report/Technology Assessment No. 99 (Prepared by RTI-University of North Carolina Evidence-based Practice Center under Contract No. 290-02-0016). AHRQ Publication 04-E022-2. Rockville, MD: Agency for Healthcare Research and Quality. July 2004.

24. Costas L, Bayas JM, Serrano B, Lafuente S, Muñoz MA. Motivations for participating in a clinical trial on an avian influenza vaccine. Trials. 2012;13:28

25. Hayes SL, Mann MK, Morgan FM, Kelly MJ, Weightman AL. Collaboration between local health and local government agencies for health improvement. Cochrane Database Syst Rev [10.1002/14651858. CD007825]. 2012. Available from: http://www.ncbi.nlm.nih.gov/ pubmed/23076937. Accessed January 15, 2013.

26. Francis D, Roberts I, Elbourne DR, et al. Marketing and clinical trials: A case study. Trials. 2007;8:37.

27. Cutts FT. Advances and challenges for the expanded programme on immunization. Br Med Bull. 1998;54(2):445-461.

28. Merkel PA, Caputo GC. Evaluation of a simple office-based strategy for increasing influenza vaccine administration and the effect of differing reimbursement plans on the patient acceptance rate. J Gen Intern Med. 1994;9(12):679-683.

29. Emanuel EJ, Wendler D, Grady C. What makes clinical research ethical? JAMA. 2000;283(20):2701-2711.

30. Schimpff SC. Vaccines in the developing world. Medpagetoday.com. Jul 2011. Available from: http://www.kevinmd.com/blog/2011/07/ vaccines-developing-world.html. Accessed January 15, 2013.

31. Saat Z, Abdul Rashid TR, Yusof MA, et al. Seasonal influenza virus strains circulating in Malaysia from 2005 to 2009. Southeast Asian J Trop Med Public Health. 2010;41(6):1368-1373.

32. Azziz Baumgartner E, Dao CN, Nasreen S, et al. Seasonality, timing, and climate drivers of influenza activity worldwide. J Infect Dis. 2012; 206(6):838-846.

33. Chew FT, Doraisingham S, Ling AE, Kumarasinghe G, Lee BW. Seasonal trends of viral respiratory tract infections in the tropics. Epidemiol Infect. 1998;121(1):121-128.

34. Yang L, Wong CM, Lau EH, Chan KP, Ou CQ, Peiris JS. Synchrony of clinical and laboratory surveillance for influenza in Hong Kong. PLoS One. 2008;3(1):e1399.

35. Shih SR, Chen GW, Yang CC, et al. Laboratory-based surveillance and molecular epidemiology of influenza virus in Taiwan. J Clin Microbiol. 2005;43(4):1651-1661.

36. Horby P, Mai le Q, Fox A, et al. The epidemiology of interpandemic and pandemic influenza in Vietnam, 2007-2010: the Ha Nam household cohort study I. Am J Epidemiol. 2012;175(10):1062-1074. 
Vaccine: Development and Therapy

Dovepress

\section{Publish your work in this journal}

Vaccine: Development and Therapy is an international, peer-reviewed, open access journal that spans the spectrum of vaccine design and development through to clinical applications. The journal is characterized by the rapid reporting of application notes, reviews, original research and clinical studies in all therapeutic areas. Clinical outcomes, patient safety,

and programs for the development and effective, safe, and sustained use of vaccines will be a feature of the journal. The manuscript management system is completely online and includes a very quick and fair peer-review system. Visit http://www.dovepress.com/testimonials.php to read real quotes from published authors.

Submit your manuscript here: http://www.dovepress.com/vaccine-development-and-therapy-journal 